\title{
Asian Versus Western Intermission Memories: Universal Features and Cultural Variations
}

\author{
James G. Matlock, PhD \\ Parapsychology Foundation \\ Iris Giesler-Petersen, Assessor iuris \\ Hannover, Germany
}

\begin{abstract}
We compared features of Asian and Western intermission memories in a sample of 85 published reincarnation cases, 58 from seven Asian countries and 27 from five Western countries. We found non-significant differences on most variables but a highly significant $(p<.000001)$ difference regarding the environment of the after-death state, with Asian subjects more likely to recall an earthly (terrestrial) environment and Western subjects more likely to recall an unearthly (heavenly) environment. Subjects from both world areas reported nonhuman spirit entities and spirits of deceased relatives and friends, but Western subjects reported them significantly more often, largely because of their frequent references to God and Jesus. Subjects from both world areas portrayed nonhuman entities in similar roles but tended to identify them differently, according to their respective cultural precepts. Whereas Western subjects more commonly perceived God and Jesus to be the Entities in Charge of the heavenly environment, Asian subjects more often saw Yama or the King of Death in that role. We found that features of the intermission experience were remarkably similar in Asian and Western cases on the whole and concluded that most of the differences may be traced to cultural expectations and interpretations.
\end{abstract}

KEY WORDS: reincarnation, intermission memories, near-death experiences, life after death, afterlife

James G. Matlock, PhD, is an anthropologist and Research Fellow affiliated with the Parapsychology Foundation, Greenport, NY. He has a long-standing interest in reincarnation, near-death experiences, and survival-of-consciousness-related issues. Iris Geisler-Petersen, Assessor iuris, is a German lawyer with similar interests. Matlock and Giesler-Petersen are co-administrators of the Facebook group Signs of Reincarnation. Correspondence regarding this article should be sent to Dr. Matlock at e-mail: jgmatlock@yahoo.com. 
Allan Kellehear (1996, 2008) and others (e.g., McClenon, 1994, chap. 9; Murphy, 2001a, n.d.; Pasricha, 1992, 2008) have provided reviews and examples of near-death experiences (NDEs) in non-Western contexts that have shown that although the basic structure of the experience holds cross-culturally, many of the features that have come to define it in the public imagination-among them the tunnel, light, and life review-are largely confined to Western countries. In this paper, we demonstrate that cultural impacts are apparent also in a related set of experiences, that is, experiences of the intermission-the interval between lives-in reincarnation cases. Ian Stevenson (2001, and elsewhere) called these accounts "intermission memories," and that term has become established in the literature (e.g., see Sharma \& Tucker, 2004).

We should state at the outset that we believe that reincarnation is the only intellectually defensible conclusion that can be reached from the case data that have been assembled over the last 50 years. One of us has reviewed these data elsewhere (Haraldsson \& Matlock, 2016; Matlock, 1990), and we will assume reincarnation to have been demonstrated as a reality for at least some persons without entering into evidential debates about it.

Poonam Sharma and Jim B. Tucker (2004) analyzed 35 Burmese intermission memories and identified three stages of the intermission experience. The first stage involved separation from the body. The second stage involved existence in a fixed location, such as a pagoda or a tree. The third stage involved the selection of the parents for the next life and return to a body. We focused on these three stages because they are the ones most commonly recalled in reincarnation cases; however, this model may be extended to include a fourth stage, life in the womb, and a fifth stage, memories of birth and its immediate aftermath (Ohkado, 2015; Ohkado \& Ikegawa, 2014). Few cases include memories of more than three of the five stages, but the memories overlap, collectively leaving the impression of a continuous experience from death to birth, only some segments of which are recalled by any given individual.

In contrast to NDEs, in most reincarnation cases-and in all but three of those with intermission memories - the subjects were between 2 and 4 years old when they first related their experiences. Children with intermission memories made significantly more verified statements about the previous life than did children without intermission memories and were more likely than other children to recall more than one previous life (Sharma \& Tucker, 2004, p. 103). Veridical per- 
ceptions of the material world-perceptions verified as accurate-can occur during all five stages of the intermission experience (Rivas, Carman, Carman, \& Dirven, 2015), as they can with NDEs (Holden, 2009; Rivas, Dirven, \& Smit, 2016). These findings should warrant careful attention to what children describe of their intermission experiences, but, as with NDEs, extensive individual and cultural variation makes it difficult to take what they say at face value.

In this paper we do not attempt a rigorous comparison of intermission experiences and NDEs, but we call attention to parallels where appropriate, and we should make clear the basis on which we do this. Intermission experiences and NDEs obviously differ in that neardeath experiencers (NDErs) return to the same bodies, whereas the recounters of intermission memories seemingly died but were reborn in new bodies. Nevertheless, there may be a profound congruence between the two types of experience. We adhere to the view that the brain transmits rather than generates consciousness (Grosso, 2015; Kelly \& Presti, 2015) and believe that NDEs come about when the brain's hold on consciousness is reduced or impaired. If that is so, the first stages of the NDE may be similar to the first stages of the intermission experience, even if in NDEs the connection to the body is not severed completely or permanently. We do not consider it significant that intermission memories come mostly from children and NDEs mostly from adults. A substantial number of children have reported NDEs (Sutherland, 2009); moreover, in the great majority of reincarnation cases, children are recalling the aftermaths of deaths as adults.

\section{Method}

We set out to evaluate Sharma and Tucker's (2004) three-stage model of the intermission experience, derived from Burmese cases, against a multicultural sample. It soon became apparent that there were important differences between Asian and Western experiences, and we decided to examine these as well, using statistical tests of coded variables. We had insufficient data to compare cases from different countries or cultures within these world areas or to compare them to cases from small-scale tribal societies. Matlock (n.d.) addresses the latter topic in a paper under review.

We began by searching the reincarnation literature through 2016 for cases that met our selection criteria: past-life memories with firsthand witnesses reported spontaneously rather than during age regression under hypnosis. We excluded sources in languages other than 
English in order to avoid bias toward languages we were able to read. We elected not to utilize accounts recorded in Internet forums or social media or unreported cases currently under investigation by us or others. We did not consider prebirth memories that did not also include memories of a previous life; although phenomenologically similar to intermission experiences, it is not certain that the former experiences involve reincarnation.

We found about 400 reincarnation cases that met our criteria. Of these, 85 (21\%) included reference to the intermission. This figure compares to Sharma and Tucker's (2004) finding of intermission memories in 276 (23\%) of 1,200 reincarnation cases in a database compiled by the Division of Personality Studies (now the Division of Perceptual Studies [DOPS]) of the University of Virginia School of Medicine. The number of cases per country varied in both Sharma and Tucker's sample and ours. Our sample represented 12 countries, seven Asian and five Western. Among our seven Asian countries, India, Thailand, and Myanmar (Burma) contributed 15 cases each; another 5 cases came from Sri Lanka, 3 from Turkey, 3 from Lebanon, and 2 from Japan. Among our five Western countries, 11 cases came from the United States, 9 from the United Kingdom, 5 from the Netherlands, 1 from Hungary, and 1 from Finland.

Nearly half of our cases - a total of $38(45 \%)$-were drawn from the works of Ian Stevenson (Stevenson, 1974, 1975, 1977, 1980, 1983b, 1997, 2003; Stevenson \& Samararatne, 1988), with the remainder contributed by 16 other authors: Mary Rose Barrington, Peter Mulacz, and Titus Rivas (2005), Carol Bowman (2001), George Brownell (1949), Parmeshwar Dayal (1988), Harold Fielding-Hall (1898), Erlendur Haraldsson (2000; Haraldsson \& Matlock, 2016), Peter and Mary Harrison (1983/1991), Lafcadio Hearn (1897), Antonia Mills (Mills, 1989; Mills \& Dhiman, 2011), Karl Muller (1970), Masayuki Ohkado (2016), Titus Rivas (2001, 2003, 2004; Rawat \& Rivas, 2007), K. K. N. Sahay (1927), Tom Shroder (1999), Francis Story (1975), and Jim B. Tucker (2005, 2013).

Four of our cases were reported at the end of the 19th century by Hearn (1897) and Fielding-Hall (1898), but the great majority emerged after 1960, when Stevenson began his field investigations. The Fielding-Hall (1898) case involved twins, but because the twins' intermission memories were not distinguished, we coded them as a single case. In the Rivas (2001) case, two intermissions were recalled, but we coded only the most recent one. Our sample overlapped with that of Sharma and Tucker (2004) but was not a subset of it. 
We did not begin with any theoretical expectations or formulate any hypotheses in advance of our statistical tests. We coded cases independently and discussed discrepancies until we reached agreement. We coded cases on several variables of interest to reincarnation research, such as age of first speaking about the past life, age and cause of death in the past life, relationship between the previous person and the subject's family, and length of intermission, in addition to variables specific to the intermission memories themselves.

All of our tests were performed by Fisher's exact method using online calculators provided by Vassar College (http://vassarstats.net/ tab2x2.html; http://vassarstats.net/fisher2x3.html) and are reported with two-tailed probability values. We set an alpha of .05 for claims of statistical significance. To conserve space, we present our results in tables only for tests with significant outcomes. Full results of all tests, along with complete coding data and source documentation, are available in a PDF file that may be downloaded from Matlock's personal web site (http://jamesgmatlock.net/resources/supportingdocs/).

\section{Core Features of Cases with Intermission Memories}

We performed several tests designed to assess how similar Asian and Western cases with intermission memories were in their core features. Under the Discussion heading below, we consider how the cases of our sample compare with reincarnation cases without intermission memories and how our sample relates to Sharma and Tucker's (2004) sample.

\section{General Case Characteristics}

Solved vs. unsolved cases. When the deceased person whose life a subject claims to recall is identified, a case is said to be solved; when no identification can be made, the case is considered unsolved. Reincarnation cases may remain unsolved for many reasons: A subject may not remember the previous life in sufficient detail for the previous person to be traced, the subject may be mistaken about crucial facts, and/or the previous life may have transpired further back in time than investigators are able to check or in a location they cannot reach. Some unsolved cases may be fantasies, in whole or in part.

We compared the proportion of solved to unsolved cases with intermission memories in Asian versus Western countries and found sig- 
Table 1 Solved vs. Unsolved Reincarnation Cases With Intermission Memories in Asian vs. Western Countries

\begin{tabular}{lccc}
\hline Area & Solved & Unsolved & Total \\
\hline Asia & 50 & 8 & 58 \\
West & 13 & 14 & 27 \\
Total & 63 & 22 & 85 \\
\hline
\end{tabular}

nificantly more unsolved cases in Western countries $(p<.0005)$; see Table 1.

Because there was no statistically significant difference between solved and unsolved cases on any other test, for the remainder of this paper we show the results for combined samples. For figures for solved vs. unsolved cases independently, see http://jamesgmatlock.net/ resources/supportingdocs/.

Quality of investigation and description. In addition to our sample containing fewer Western cases, a higher proportion of which were unsolved, the Western cases tended to be less well investigated and described than Asian cases. Whereas Stevenson investigated cases over a period of years and often described them in detail, other researchers have rarely met his standards. We judged a case to be well investigated and described when the report included the interview testimony of more than one witness and a description of the remembered past life in addition to the intermission experience itself. We judged a case to be poorly investigated and described when the report contained the testimony of a single witness and only a brief description of the case with little attention to details. We noted that quality of investigation and description were closely related, so we saw no reason to distinguish these variables.

We considered many of our older Asian cases (e.g., Fielding-Hall, 1898) as well as several unsolved modern Western cases (e.g., Bowman, 2001) to have been poorly investigated and described. The date of the case alone did not predict how well it was investigated and described, however; one older case (Hearn, 1897) was among the betterinvestigated and better-described cases in our sample. We detected no relationship between how well investigated and described the cases were and whether or not they were solved with Asian cases, Western cases, or a combined sample ( $p=.371$ ), so the varying quality of investigation and description of cases was unlikely to have had an important influence on our tests. 


\section{Major Case Features}

Natural vs. violent death. We looked at the number of cases in which the previous person was known (in solved cases) or purported (in unsolved cases) to have died naturally or violently. Natural deaths were usually by illness. Violent deaths were by accident, by murder, or during war.

A total of 21 Asian and 8 Western cases featured natural deaths, and 33 Asian and 13 Western cases featured violent deaths. The difference in the proportions of natural vs. violent deaths in Asian vs. Western cases was not statistically significant $(p=.841)$.

Relationship status. The relationship between the previous person and the subject of a reincarnation case (the "relationship status") has been of great interest to reincarnation researchers. We classified relationships as family, acquaintance, or stranger. The family category included cases in which the previous person and the subject were known to be related genetically. Acquaintance relationships included chance encounters as well as strong friendships between the families of the subject and previous person. When there was a stranger relationship, the previous person and his family were entirely unknown to the subject's family before the subject began to speak about the past-life memories.

Table 2 shows the number of family, acquaintance, and stranger cases in the Asian and Western countries of our sample. Because unsolved cases are stranger cases almost by definition-if the previous person was known to the subject's family, the likelihood is high that he would have been identified as the person about whom the subject was talking - this test was restricted to solved cases. In one case (the Okshitgon twins, contributed by Fielding-Hall, 1898), the relationship was unclear, and we excluded this case from our test. The difference

Table 2 Family, Acquaintance, and Stranger Relationships in Solved Cases With Intermission Memories

\begin{tabular}{lcccc}
\hline & \multicolumn{3}{c}{ Relationship } & \\
\cline { 2 - 4 } Area & Family & Acquaintance & Stranger & Total \\
\hline Asia & 9 & 4 & 36 & 49 \\
West & 7 & 1 & 5 & 13 \\
Total & 16 & 5 & 41 & 62 \\
\hline
\end{tabular}


between the remaining Asian and Western cases was statistically significant $(p=.032)$.

Other variables. Casual inspection of the data we coded did not reveal noteworthy patterns on other variables and we will not explore other relationships here. Interested readers may consult the PDF file available at http://jamesgmatlock.net/resources/supportingdocs/.

\section{Discussion}

That the majority of cases with intermission memories come from Asian countries is not surprising, because many more Asian than Western reincarnation cases have been reported in the literature. Stevenson and his colleagues worked primarily in Asia, where the cases are easier to find (Stevenson, 2001). Asian cases also tend to be more readily solved than Western cases. Cook, Pasricha, Samararatne, Maung, and Stevenson (1983, p. 117) showed that the proportion of solved cases varied by country: $92 \%$ in Thailand, $80 \%$ in Burma, $72 \%$ in India, but only $20 \%$ in the United States, the only Western country they considered.

Our finding of fewer solved cases with intermission memories in Western countries (Table 1) thus is in line with the DOPS collection. Our finding of fewer stranger cases among solved cases with intermission memories in the West (Table 2) is consistent with there being fewer solved Western cases in general, because stranger cases are a good deal harder to solve than are cases with family and acquaintance relationships. Of 79 solved American cases known to Stevenson in 1983, all but one was a family case (Stevenson, 1983a, p. 744).

We found more violent deaths than natural deaths in both Asian and Western cases in our sample. Violent deaths figured in 46 (55\%) of our 85 cases. This also is in accord with figures from other studies. Cook et al. (1983, p. 128) reported the rate of violent death was $61 \%$ in a combined sample of solved and unsolved cases and $51 \%$ for solved cases alone.

Cook et al. (1983) determined that solved and unsolved cases were very similar in their main features, the most significant differences being that in unsolved cases there was a higher incidence of violent death and a more frequent failure to recall the name of the previous person. The close similarity in solved and unsolved cases makes us feel justified in having grouped together solved and unsolved cases for our tests. 
Sharma and Tucker (2004, pp. 103-104) compared cases with intermission memories to cases without them in the DOPS database. They found that subjects of cases with intermission memories made significantly more accurate statements about the previous life; they remembered more names from the previous life, including that of the previous person; they were more likely to recall the death of the previous person; and they recalled more past lives. Cases with intermission memories were stronger overall, as measured by Tucker's (2000) Strength of Case Scale. In other ways, there were no significant differences: There were no differences in the sex of the subject, the age at which the subject began to speak about a previous life, the number of birthmarks and birth defects, or the mean distance between the place where the previous person died and the subject was born.

Without access to Sharma and Tucker's (2004) original data, we cannot compare our sample directly to theirs, but because our cases did not differ from the larger case collection on several key variables, it seems unlikely that our samples differed substantially. Our studies varied primarily in that Sharma and Tucker's analysis of the structure of intermission memories was based exclusively on Burmese cases (which were excluded from their statistical pattern analyses), and our sample was a multicultural one.

\section{Stages of the Intermission Experience}

\section{The Nature of Intermission Stage 1}

Sharma and Tucker (2004) wrote:

The first stage could be named the "transitional stage." Nine [26\%] of 35 Burmese intermission subjects recalled characteristics typical of this period. While interview notes rarely document any references by subjects to their emotional state during the intermission period, the events recalled during the transitional stage would often seem uncomfortable or unpleasant to the Western reader. The events and characters described are associated with the previous life. Subjects may see the preparation of the previous personality's body or the funeral or try to contact grieving relatives, only to find they are unable to communicate with the living. One subject said he did not realize he was dead. Several reported being driven away by the weeping of their relatives, an experience that one subject said made him "hot." This stage often ends as the subject is directed by an elder or an old man dressed in white to a place where he or she then stays for the bulk of the intermission experience. (p. 107) 
Table 3 Presence vs. Absence of Stage 1 Intermission Memories

\begin{tabular}{lccc}
\hline & \multicolumn{2}{c}{ Stage 1 Memories } & \\
\cline { 2 - 3 } Area & Present & Absent & Total \\
\hline Asia & 25 & 33 & 58 \\
West & 5 & 22 & 27 \\
Total & 30 & 55 & 85 \\
\hline
\end{tabular}

A total of $30(35 \%)$ of the 85 cases in our sample included content that resembled Sharma and Tucker's (2004) intermission Stage 1. In our sample, as in theirs, Stage 1 began with death and often concluded with cremation or burial. Sometimes the deceased was met by a spirit who acted as an escort for the remainder of the intermission experience, but on the whole, the events and persons perceived were realistic impressions of the material world.

Stage 1 content was more common in Asian cases than in Western cases in our sample: Whereas 25 (43\%) of our 58 Asian cases included Stage 1 intermission memories, only $6(22 \%)$ of our 27 Western cases did; see Table 3 . The difference in these proportions was statistically significant $(p=.031)$.

Stage 1 perceptions of the material world. Perception of the material world is a key feature of Stage 1 intermission memories. Perceptions were reported frequently in both Asian and Western countries. Three-year-old Thiang San Kla of Thailand said that he saw his previous body after death and wanted to return to it, but there were so many people around, he was afraid to do so (Stevenson, 1997, vol. 2, p. 1585). Sometimes the perceptions were veridical. Another Thai boy, Bongkuch Promsin, recalled that after killing him, his murderers carried his body into the field where it was found (Stevenson, $1983 \mathrm{~b}$, p. 109). The accuracy of perceptions was confirmed in $11(44 \%)$ of 25 solved Asian cases and in 3 (100\%) of 3 solved Western cases. In other cases the perceptions were plausible but uncorroborated. In no cases in our sample were the perceptions shown to be erroneous or implausible.

All but a few memories of Stage 1 perceptions occurred in the waking state. They came during sleep to two Dutch subjects, Christina K. and an unnamed girl (Rawat \& Rivas, 2007, pp. 197-198; Rivas, 2004, pp. 19-20). A young Thai woman of 20, Pratomwan Inthanu, was meditating when she recalled events from two previous lives as well 
as the intermission between her most recent past life and her present one (Stevenson, 1983b, pp. 157-160, 168-169).

In two cases, subjects reported awareness of something that happened after death that implied perception at that time, although they did not explicitly say this. Disna Samarasinghe knew that her previous body was buried near an anthill (Stevenson, 1977, pp. 105-106). Cevriye Bayrı knew that a baby had been born to the woman whose life she recalled after her murder (Stevenson, 1980, p. 257). We coded these instances as perception present. With these cases included, all 30 Stage 1 memories in both Asia and the West included perceptions of the material world. Even if these last two cases were not counted as perception present, there was no statistically significant difference between Asian and Western cases in the presence or absence of perceptions during Stage $1(p=.10)$.

The conclusion of Stage 1. In agreement with Sharma and Tucker (2004), we found that Stage 1 concluded when the spirit of the deceased moved away from the site of death or disposal of the body, either alone or with an escort. We found spirit escorts in 5 (25\%) of 20 Asian cases and in $1(33 \%)$ of 3 Western cases where the reason for the conclusion of Stage 1 was specified. Subjects in the remaining cases described leaving on their own volition. There was no statistically significant difference between Asian and Western countries in the proportions of leaving with a spirit escort or on its own $(p=1.0)$.

At the conclusion of Stage 1, intermission experiences normally proceeded to Stage 2. However, a few subjects in our sample remembered selecting their parents at the end of Stage 1, thus jumping directly to Stage 3. Usually this choice occurred in association with perceptions of the material world, when the individual decided to follow parentsto-be. An Indian boy named Sunder Lal recalled having been a man who had died of plague. After his death the man's body was thrown into a river where Sunder Lal's mother-to-be happened to be bathing; he saw her and accompanied her home (Sahay, 1927, p. 17). Stevenson (2001, pp. 240-242) termed the new parents' coming into contact with a deceased body or place of death a "geographic factor" in reincarnation. Geographic factors accounted for skipping Stage 2 in three cases from our sample: two from Myanmar, in addition to Sunder Lal's from India.

Tunnel and light impressions were rarely mentioned in either Asian or Western intermission memories. Purnima Ekanayake said that she stayed for a while in semi-darkness, then saw a light, went toward 
it, and was reborn (Haraldsson, 2000, p. 18). Ryan Hammons, whose case we did not count as including Stage 1 memories due to the lack of detail, told his mother that when one died one saw a light toward which one should move (Tucker, 2013, p. 89). An English girl told her parents that she went through a "long tunnel" on her way to Heaven, where she met God (Bowman, 2001, p. 137).

\section{The Nature of Intermission Stage 2}

Regarding intermission Stage 2, Sharma and Tucker (2004) wrote:

The second stage is characterized by its marked stability compared to the other two stages. Subjects report living in a particular location or having a schedule or duties to which they must attend. Of the 35 cases so far analyzed, 19 [54\%] had reports typical of the second stage. Nine reported staying in a tree, four in a pagoda, and two remained near the place of death. Reports of seeing or interacting with other discarnate personalities are common (seven subjects). Subjects report varying degrees of comfort during this period. One subject reported being abused by other spirits who threw objects at him, and having to walk long distances. Another woman reported not being able to leave the site where she had buried her jewelry in life, but said that she was far more beautiful as a discarnate and had pretty dresses of gold. Another woman, however, who is very poor in her current life, reported that all her needs were taken care of as a discarnate and that her experience was "quite pleasant." (pp. 107-108)

A total of 66 (78\%) of our 85 cases included content that corresponded to Sharma and Tucker's (2004) intermission Stage 2, although it did not necessarily pass in a fixed location. Subjects in $44(76 \%)$ of our 58 Asian cases and $22(81 \%)$ of our 27 Western cases talked about their memories of discarnate existence. The difference was not statistically significant $(p=.764)$.

Stage 2 perceptions. In our sample, perceptions of specific events in the material world, although not as common as in Stage 1, were not unusual in Stage 2. They were reported in 25 (57\%) of 44 Asian cases and in 7 (38\%) of 27 Western cases, a difference which approached but did not reach significance $(p=.07)$.

Perceptions were veridical in 8 Asian and 3 Western cases. For example, an Indian boy, Veer Singh, said that during an 11-year intermission he had resided in a peepal tree in his former family's yard. From that vantage point, he became aware that the family purchased a camel and was engaged in lawsuits, and he stated the names of (and 
later recognized) two children born after his death. On one occasion, he became annoyed with two women swinging from a branch of his tree and caused the plank on which they were seated to break. All of these incidents had occurred as Veer described (Stevenson, 1975, pp. 328-329).

Terrestrial vs. heavenly Stage 2. One of the notable things about Sharma and Tucker's (2004) description of intermission Stage 2 is the impression it gives of time spent closely tied to the earth. Of their 19 subjects who spoke about Stage 2, "nine reported staying in a tree, four in a pagoda, and two remained near the place of death" (Sharma \& Tucker, 2004, p. 108). We too found many Asian cases with memories of what we will call a "terrestrial" as opposed to a "heavenly" Stage 2 environment. Of our 66 cases with Stage 2 memories, 30 referred to a terrestrial environment, 27 referred to a heavenly environment, and 5 referred to both terrestrial and heavenly environments (with movement between them), whereas the nature of the postmortem environment was not clear in 4 cases.

Veer Singh's memories of the peepal tree are an example of a terrestrial environment. By contrast, an English girl, Nicola Wheater, told her parents, "I went to sleep and died and I saw God in Heaven before I was born" (Harrison \& Harrison, 1991, p. 13). When both terrestrial and heavenly environments were described, case subjects said they spent most of their time in heaven but sometimes visited the earth. An Indian girl, Pratima Saxena, said that she "went up" after she died but whenever her (previous) son was in trouble, she "came down" to attend to him (Stevenson, 1997, vol. 1, p. 594). A Thai girl, Ratana Wongsombat, said that she went first to heaven but came down to look for something she had left in a meditation hut (Stevenson, 1983, p. 36). The unnamed Dutch girl mentioned above told her mother, "I was with the angels in the sky and I looked down upon the earth. . . . I flew to the earth, walked into a house and looked around" (Rawat \& Rivas, 2007, p. 197).

Memories of terrestrial, heavenly, and both environments were not evenly distributed between Asia and the West. Of the 30 terrestrial cases, 28 (93\%) occurred in Asian countries, whereas of the 27 heavenly cases, $19(70 \%)$ occurred in Western countries. Both environments were described in 4 Asian cases and 1 Western case. The nature of the postmortem environment was unclear in four Asian cases, and these were excluded from our test; see Table 4 . The difference between Asian and Western Stage 2 experiences in those cases in which 
Table 4 Terrestrial vs. Heavenly Stage 2 Intermission Memories

\begin{tabular}{lcccc}
\hline & \multicolumn{3}{c}{ Afterlife Environment } & \\
\cline { 2 - 4 } Area & Terrestrial & Heavenly & Both & Total \\
\hline Asia & 28 & 8 & 4 & 40 \\
West & 2 & 19 & 1 & 22 \\
Total & 30 & 27 & 5 & 62 \\
\hline
\end{tabular}

subjects described a postmortem environment was highly significant $(p<.000001)$.

Nature of entities encountered. As Sharma and Tucker (2004) observed, reports of seeing or interacting with discarnate spirit entities are common during intermission Stage 2. However, whereas discarnate entities were cited in $7(20 \%)$ of their 35 cases, they were cited in $41(48 \%)$ of our 85 cases. Western cases in our sample contributed disproportionately to this finding, with spirit entities reported in 22 (50\%) of 44 Asian cases and 19 (86\%) of 22 Western cases (see Table 5). This difference was statistically significant $(p=.009)$.

We grouped the spirits our subjects encountered into two broad categories: nonhuman spirits, often religious entities such as God or Jesus in the West and others in Asia; and human spirits, including deceased relatives or friends along with anonymous spirits we designated the General Population. In Asia, nonhuman spirits were reported in $16(73 \%)$, human spirits in $5(22 \%)$, and both nonhuman and human spirits in $1(5 \%)$ of 22 cases; in the West, nonhuman spirits were reported in 7 (37\%), human spirits in 3 (16\%), and both nonhuman and human spirits in 9 (47\%) of 19 cases (see Table 6$)$. The difference between these proportions was statistically significant $(p=.005)$.

Table 5 Presence vs. Absence of Spirit Entities Encountered During Stage 2 Intermission Memories

\begin{tabular}{lccc}
\hline & \multicolumn{3}{c}{ Spirits } \\
\cline { 2 - 3 } Area & Present & Absent & Total \\
\hline Asia & 22 & 22 & 44 \\
West & 19 & 3 & 22 \\
Total & 41 & 25 & 66 \\
\hline
\end{tabular}


Table 6 Nonhuman vs. Human Spirits During Stage 2 Intermission Memories

\begin{tabular}{lcccc}
\hline & \multicolumn{3}{c}{ Spirits } & \\
\cline { 2 - 4 } Source & Nonhuman & Human & Both & Total \\
\hline Asian & 16 & 5 & 1 & 22 \\
Western & 7 & 3 & 9 & 19 \\
Total & 23 & 8 & 10 & 41 \\
\hline
\end{tabular}

Nature of human spirits. We examined the proportions of family and friends and members of the General Population in Asian versus Western cases. In Asia, family or friends were encountered in 4 (67\%) and members of the General Population in $2(33 \%)$ of 6 cases. In the West, family or friends were encountered in 4 (34\%), members of the General Population in 7 (58\%), and both family and friends and members of the General Population in 1 (8\%) of 12 cases. The differences in the proportions between Asia and the West was not significant ( $p=$ $.556)$.

Roles of nonhuman spirits. In both Asian and Western cases, nonhuman spirit entities appeared in similar roles. We designated these roles Gatekeeper, Escort, Entity in Charge, and Other. Gatekeepers appeared at the opening of Stage 2 experiences and checked records. Escorts met the discarnate spirit at the start of Stage 2 (sometimes at the end of Stage 1) and guided the spirit for at least a portion of the Stage 2 experience. Entities in Charge were credited with overseeing the Stage 2 environment and sometimes also made decisions about the fate of the discarnate spirit. Other nonhuman spirits had no distinctive roles.

Entities with various roles appeared in both terrestrial and heavenly environments in both Asian and Western cases. Although Entities in Charge were more likely to appear in heavenly environments, especially in Western cases-in Asia, 4 (80\%) out of 5 Entities in Charge appeared in heavenly environments, whereas in the West, 12 (100\%) of 12 Entities in Charge appeared in heavenly environmentsthe difference was not significant $(p=.092)$.

Representation of entities in different roles. Although entities in the major roles appeared in both Asian and Western cases, subjects from the two world areas identified them differently. In Asian cases an Escort typically was described as an old man or sage, often dressed in 
white; in Western cases, it was a generic man or woman. In Asia, entities in the Other role included devas and patron deities; in the West, they were described as angels. The Entity in Charge was perceived as God, Yama, or the King of Death in Asia, but as God or Jesus in the West.

Stage 2 activities. Contrary to Sharma and Tucker's (2004) finding, none of our subjects mentioned working during Stage 2 of the intermission. Most said that they hung out or walked about, sometimes with an escort; only on rare occasions did they report other activities. Four subjects, including Pratima Saxena (Stevenson, 1997, vol. 1), recalled sending dream messages to loved ones left behind. Three Asian subjects said they faced judgments or punishments after death, and two spoke about having taken stock of their former lives. Nasir Toksöz, a Turkish Alevi boy, said that at death he went before God and gave him a report of his conduct (Stevenson, 1980, p. 335). Kazuya, a Japanese boy, said that after killing himself he spent some time in a "reflection room" before deciding to be reborn to his former mother. Kazuya also said that he made a prebirth compact with three other spirits to be reborn around the same time; when they met after reincarnating, the children recognized each other (Ohkado, 2016, pp. 529-530). Only one of our subjects remembered setting goals or planning any aspects of their new lives, apart from selecting their parents.

\section{The Nature of Intermission Stage 3}

According to Sharma and Tucker (2004):

The final stage is one of choosing parents for the next life or of conception. Eighteen [51\%] of 35 subjects reported characteristics of this stage. Seven reported following the future parents home, apparently on their own initiative, as the parents passed by while performing everyday tasks, such as bathing or returning home from work. Five more reported being directed to the present parents, often by elders or the old man figure referred to in stage 1 . Nine commented on how they gained entrance to the mother's body. This was most often by transforming into a grain of rice or speck of dust in the water and being ingested by the mother. A few went to considerable lengths, having to try repeatedly when either they were rebuffed by guardian spirits or the water was thrown out as dirty. (p. 108)

In our sample, 42 (49\%) of the 85 subjects reported experiences that corresponded to Sharma and Tucker's (2004) Stage 3: 29 (50\%) of our 
Table 7 Presence vs. Absence of Perception of Material World During Intermission Stage 3

\begin{tabular}{lccc}
\hline & \multicolumn{2}{c}{ Perception } & \\
\cline { 2 - 3 } Area & Present & Absent & Total \\
\hline Asia & 16 & 13 & 29 \\
West & 2 & 12 & 14 \\
Total & 18 & 25 & 43 \\
\hline
\end{tabular}

58 Asian and 14 (52\%) of our 27 Western subjects talked about how they came to their parents. Once more, the difference in the proportions was not statistically significant $(p=1.0)$.

Stage 3 perceptions. Perceptions of the material world were reported in $16(55 \%)$ of 29 Asian cases and in $2(14 \%)$ of 14 Western cases with Stage 3 intermission memories (see Table 8). This difference was statistically significant $(p=.019)$.

The perceptions occurred in both terrestrial and heavenly environments. They were veridical in 3 Asian and 2 Western cases. Bongkuch Promsin said that he had tried to return to his previous mother, but had gotten lost in the village market on a rainy day; he had seen his present father, and accompanied him home on a bus. As it happened, Bongkuch's father had been in the market on a rainy day during the month that his wife became pregnant, and had returned home on a bus (Stevenson, 1983b, p. 109). James Leininger told his parents that he found them on the beach in Hawaii and accurately described the pink hotel in which they had vacationed there 11 months before his birth (Tucker, 2013, p. 87).

Elective vs. assisted reincarnation. Sharma and Tucker (2004) observed that some subjects recalled choosing their parents on their own initiative, whereas others said they had assistance from spirit entities. Both alternatives were represented in our sample as well. When there was assistance, the assisting spirit sometimes selected the new parents, but often it merely shaped the decision of where to be reborn. Sunita Khandelwal of India said that after falling from a balcony to her death she "went up" to a place where she met a holy man with a long beard who "checked her record" and sent her back, but to a new body, not her old one (Stevenson, 1997, vol. 1, p. 484). In this case the Gatekeeper made the determination, but more commonly an Escort or an Entity in Charge made it. 
In one of our unsolved Burmese cases the preferred avenue was blocked, and reincarnation was forced near to where death occurred. Ma Par recalled having been a British officer aboard a reconnaissance plane that ran out of fuel and crashed in Burma during World War II. As a discarnate spirit, she thought of England and went there, but the King of Death did not allow her to stay and she returned to Burma. Later she went to England a second time but again was pulled back to Burma and told she would have to be reborn there, although her new family was not designated (Stevenson, 1997, vol. 2, p. 1812).

We labelled reincarnation without assistance "elective" and reincarnation with assistance "assisted." When both elements were present, as with Ma Par, we designated it "elective-assisted." Subjects in both world areas reported elective reincarnation much more frequently than assisted: in 25 (69\%) of 36 Asian and 9 (64\%) of 14 Western cases, subjects said they chose their parents on their own initiative. Assisted reincarnation with an elective element occurred in both groups also, in 3 Asian and 2 Western cases. We found no statistically significant difference between the proportions of elective, assisted, and electiveassisted reincarnation in Asian vs. Western cases $(p=.792)$.

Geographic factors in elective reincarnation. Stevenson (2001, pp. 239-241) showed that geographic factors are important in explaining the selection of the new parents in stranger cases (see also Story, 1975, chap. 20). Geographic factors are a feature of a terrestrial environment, and so they are more likely to appear in Asia, where the terrestrial experience is more common. All 17 of our cases with geographical factors-among them Sunder Lal and Bongkuch Promsin-were Asian, and all were associated with a terrestrial Stage 2 environment. All but two were stranger cases. Maung Ying Maung recalled dying when his light plane crashed; he walked to his brother's house, where his sister-in-law saw his apparition and invited him to stay (reincarnate) with them (Stevenson, 1983, pp. 288-289). Puti Patra said she had stayed near the date palm tree by her previous home, but when her father, with whom she was then only slightly acquainted, passed by one day, she followed him home (Stevenson 1975, pp. 273-274).

The fruit of forgetfulness. In 4 (7\%) of our 58 Asian cases, subjects recalled having been offered a fruit or other food to eat. Some reincarnation case subjects credit their ability to remember previous livesand intermissions - to having avoided eating these foods (Stevenson, 
1983b, p. 7). Ampan Petcherat (Stevenson, 1983b, p. 68) and Santosh Sukla (Stevenson, 1997, vol. 1, p. 556) said that they ate the proffered fruit; nevertheless, they recalled their previous lives and the intermission before their present lives anyway.

\section{Discussion}

In comments on this paper in draft, Janice Holden wrote:

It seems to me that in Asia, where reincarnation belief is relatively greater, compared to the West where it is lower and where afterlife beliefs are dominated by Christian conceptions of a trans-material/ heavenly afterlife, these cultural differences might account for greater memory among Asians of hanging around the dead body. The cultural belief might somehow potentiate the actual experience of hanging around, and/or it might potentiate the memory of hanging around even if the actuality is equal in the Asia and the West. Maybe experiencers in the West don't do it as much because of the expectation to "move on," or maybe they do it as much but don't focus on it and, therefore, don't remember it as much - because it's not as salient/important an aspect of afterlife to them as "moving on" is. Conversely, people who believe in reincarnation may expect, and therefore enact and/or pay more attention to terrestrial interlife aspects, beginning with disengagement from the physical body and one's previous lifetime. This idea, then, corresponds to the finding that in Stage 2, Asian memories are more material/terrestrial and Western more trans-material/ heavenly. In other words, memories of a terrestrial Stage 2 may be an extension of more memories of hanging around the dead body. Thus, all the findings hang together in one coherent narrative: Asians expect to reincarnate, so they more frequently enact and/or recall material/terrestrial aspects of the interlife, beginning with the disengagement process from the previous body/lifetime; Westerners expect to go to heaven, so they more frequently enact and/or recall trans-material/ heavenly aspects including spiritual, especially God-related, entities.

We agree with Holden about cultural influences on intermission experiences, but the cross-cultural consistencies in the structure and content of the memories in our sample strikes us as remarkable as well, especially given the long time span over which the cases were reported. We found no statistically significant differences in the presence or absence of Stage 2 or 3 experiences or in many of the characteristics of those stages between Asian and Western countries. Perceptions of the material world were reported in all three stages in both world areas. A variety of spirit entities appeared in both Asian and Western cases in similar roles. Although spirit escorts appeared at 
the end of Stage 1 more often in Asian cases, the difference was not significant. In neither Asia nor the West were there reports of life planning in advance of reincarnation, and rarely were there mentions of judgment or punishment. Elective, assisted, and elective-assisted reincarnation occurred in similar proportions in both areas.

We found a statistically significant difference in the frequency of memories of Stage 1, but no significant difference in the frequency of perceptions of the material world for those who reported Stage 1 memories. The situation was reversed for Stage 3, where we found no statistically significant difference in the frequency of memories of selecting new parents but did find a significant difference in whether or not there were accompanying perceptions of the material world. These differences may be due to sampling error and, thus, may disappear when more cases are included in analyses. Most other differences were minor and statistically non-significant. Geographic factors were important in elective reincarnation in Asia but not in the West. The most significant difference we found was in the nature of the Stage 2 environment, which was more often terrestrial in Asian experiences and heavenly in Western experiences. This we think is because in Western countries, Christianity teaches that the afterlife passes in Heaven.

In keeping with our view that intermission memories-and NDEsrepresent the experiences of consciousness unconstrained by a brain, we do not think of the afterlife as a place but, rather, as a state of mind. The divergent experiences between Asia and the West we believe are the products of variant cultural conditioning carried over into death. Westerners generally expect to go to heaven when they die, whereas Asians as a group have no such presumption. We interpret shifts from terrestrial to heavenly environments as shifts in the focus of attention rather than movement between quasi-physical domains. Shifts of attention, rather than changes of location, would also help to explain how perceptions of the material world are possible during all stages of the intermission experience.

The significantly greater frequency with which spirit entities were reported in Western as opposed to Asian cases may seem surprising, but the reason becomes clearer when the data are examined more closely. A big factor is the frequency with which God was reported in Western cases. In both Asia and the West, God was personified as an Entity in Charge with whom subjects interacted and who sometimes decided on the family into which reincarnation took place. God was referenced in 2 Asian cases and 7 Western cases. In another 3 Western cases, Jesus stood in for God. An additional factor was the 
greater frequency of meeting deceased relatives and friends in Western countries. Between them, God / Jesus and the spirits of deceased family and friends accounted for the spirit entities encountered in 10 Western cases but in only 4 Asian cases, despite the larger number of Asian cases. In Asian cases, a greater variety of entities appeared and played important roles.

We noted variations in the content of the intermission experiences, but these variations may be due to contrasting expectations about the postmortem state in Asian and Western cultures. More importantly, our study confirmed Sharma and Tucker's (2004) three-stage model of the intermission experience, which was based on 35 Burmese cases. None of the 85 cases in our multicultural sample departed from Sharma and Tucker's model, although 1 Asian case and 3 Western cases included memories of Stage 4 (life in the womb), and one Western case included memories of Stage 5 (birth and its immediate aftermath), in addition to the first three stages.

The Asian case with Stage 4 memories was Thiang San Kla. Thiang said that he saw his previous body after he had been killed; he visited his friends and relations, but none could see him; he wanted to return to his old mother, but she "rejected" him (she was then past menopause), so he went to the wife of his younger brother; then, during the intrauterine period, he moved in and out of his mother's mouth (Stevenson, 1997, vol. 2, p. 1585). None of Thiang's perceptions were confirmed as veridical, unlike the memories of the American Bobby Hodges. Bobby recalled being in an aunt's womb with his younger brother, when a miscarriage ended her pregnancy; he tried to return to that womb but found it occupied, so came to his mother instead; he spoke about his parents' wedding, which occurred while she was pregnant with him; and he talked about having been born by Caesarean section. The miscarriage, the new pregnancy, his parents' wedding, and his birth had all transpired as he described (Tucker, 2005, pp. 164-168, 178; cf. Bowman, 2001, pp. 169-179, under the name Sam). The other two Western subjects with Stage 4 perceptions, also veridical, were Ryan Hammons (Tucker, 2013, p. 97) and William (Tucker, 2005, pp. 2-3, 172, 178).

\section{General Discussion and Conclusion}

The similarities of structure and content between intermission experiences and NDEs are intriguing. Intermission experiences seemingly pick up where NDEs leave off; rather than returning to one's old body, 
intermission experiencers describe a period of discarnate existence followed by the adoption of a new body. Both NDErs and intermission experiencers from different areas report perceptions, some of them veridical, of the material world. Both NDErs and intermission experiencers report encountering human and nonhuman spirit entities in the same roles. Sensations of light and darkness, and life reviews, seldom figure in intermission memories, however, and in this respect, intermission experiences are more like the non-Western NDEs identified by Kellehear $(1996,2008)$ than they are like Western NDEs.

There are other differences between NDEs and intermission experiences, even those from the same culture. In Indian NDEs, a common theme is Gatekeepers who check records and determine that the wrong person was summoned. The NDEr is sent back to his or her body and recovers, but meanwhile someone of the same name dies (Pasricha, 1992, 2008; Pasricha \& Stevenson, 1986). Gatekeepers appear less regularly in Indian intermission memories, but Sunita Khandelwal recalled having her records checked (Stevenson, 1997, vol. 1, p. 484). Several of the Thai NDEs described by Murphy (n.d.) feature Yama and his helpers, the Yamatoots. Some involved mistaken identity on the Indian model, but others depicted judgment by Yama, tortures, and tours of hell akin to the medieval European NDEs described by Zaleski (1986). The only intermission memory of similar character comes from the Thai boy Chanai Choomalaiwong (Stevenson, 1997, vol. 1, p. 313).

In the West, NDErs report having encountered God, Jesus, angels, and deceased relatives and friends, but rarely other entities. For Westerners, angels take on the roles ascribed to other entities in Asia (Lundahl, 1992). The roles of Entity in Charge, Gatekeeper, and Escort (or Guide) appear in NDE accounts from the medieval period in the West (Zaleski, 1986) as well as China and Japan (McClenon, 1994, chap. 9). They appear also in Western prebirth memories (Carman \& Carman, 2013; Rivas et al., 2015) and in other experiences related to death and dying. A man in white-a common Asian representation of the Escort figure-appeared in an Indian deathbed vision recounted to Osis and Haraldsson (2012).

That the same entity roles figure in these different classes of experience calls for some sort of explanation. Zaleski (1986) treated medieval and modern NDEs alike as narratives constructed in the telling. McClenon (1994) argued that NDEs provided an empirical grounding for religious beliefs but attributed them to changes in brain physiology. Murphy (2001b) offered a Buddhist view of how premortem be- 
liefs could be related to states of consciousness at death. C. G. Jung $(1954,1959 / 1981)$ understood spirits to be archetypes, that is, symbols arising from a collective unconscious that are presented to the conscious mind in accord with local precepts and values. These interpretations all avoid the seemingly obvious possibility that the entities are objectively real, but we believe this possibility deserves to be taken seriously.

We think that what survives death and reincarnates is best conceived of as a stream of consciousness continuous with the stream of consciousness experienced in embodied life. It appears from intermission memories that discarnate streams of consciousness-spiritsretain their mental faculties to a considerable extent. They are able to communicate with other spirits and embodied minds using telepathy and perceive the terrestrial world through clairvoyance. Telepathy and clairvoyance are varieties of extrasensory perception which, together with psychokinesis, form the ability parapsychologists call psi.

The nonhuman entities encountered during near-death, intermission, and kindred experiences we consider to be streams of consciousness also. These entities have nonhuman characteristics and apparently are unable to incarnate in human bodies, yet they interact with discarnate human spirits-and sometimes incarnate ones as well. The interactions are reportedly not through spoken words, but through thoughts and impressions - in other words, through psi.

Rivas et al. (2016) showed how verified psi perceptions and interactions are involved in NDEs, and psi is central to our conception of what is happening in intermission experiences as well. We presume that consciousness maintains its structure while discarnate and includes both subconscious and conscious strata. During embodied life, psi impressions are processed at the subconscious level before being presented to conscious awareness (Marshall, 2015, pp. 394-401), and there is little reason to think that the same would not obtain during disembodied existence. We suggest that it is during this subconscious processing that cultural overlays enter, so that mental images related to psi impressions conform to the cultural conditioning of a discarnate experiencer's most recent embodied life. The same process would account for the hallucinatory features in NDEs emphasized by Augustine (2007).

From this perspective, the spirit entities encountered in intermission and related experiences are objectively real, although they are experienced subjectively. Are the events of discarnate existence then equally real? We find this question harder to answer, because much 
of what experiencers recount appears to be as strongly shaped by cultural ideals as the entities' identities are. Perhaps there are variations in social practices in discarnate existence, just as there are in embodied life. This possibility is not untenable, but we see no way to evaluate it with currently available data.

Interestingly, the same basic elements - the three-stage structure, perceptions of the material world, encounters with human and nonhuman spirits - appear also in intermission memories from native American tribal societies. However, these Amerindian experiences introduce another version of the Stage 2 environment: Among the Tlingit of Alaska and the Winnebago of Wisconsin, the deceased do not remain anchored in the material world but travel through that world to reach the land of the dead, which lies beyond it on the same plane. The Tlingit imagine that only those who die violently ascend to the heavens (Matlock, n.d.).

An instructive variation was collected in 1966 from the Kutchin (Gwich'in) of Canada's Northwest Territories, who had been in contact with Christian missionaries. A 6-year-old girl told her mother that after she died before, she walked up to the sky on a steep and narrow trail. St. Peter met her at the gate to heaven and admitted her. She walked on until she met Jesus, who told her that it was not her time to die and sent her back to earth to be reborn as her sister (Slobodin, 1994, p. 151). This example shows clearly how the intermission experience is affected by culturally-instilled ideas. The cultural overlays must be stripped off before the underlying patterns become visible. We believe that the cross-cultural commonalities in intermission memories hint at universal processes in reincarnation, and the similarities between them and NDEs suggest that these phenomena should be considered part of the same continuum of experience.

\section{References}

Augustine, K. (2007). Near-death experiences with hallucinatory features. Journal of Near-Death Studies, 26, 3-31. doi:10.17514/JNDS-2007-26-1-p3-31.

Barrington, M. R., Mulacz, P., \& Rivas, T. (2005). The case of Iris Farczády-A stolen life. Journal of the Society for Psychical Research, 69, 49-77.

Bowman, C. (2001). Return from heaven: Beloved relatives reincarnated within your family. New York, NY: HarperCollins.

Brownell, G. B. (1949). Reincarnation (2nd ed.). Santa Barbara, CA: Aquarian Ministry.

Carman, E. M., \& Carman, N. J. (2013). Cosmic cradle: Spiritual dimensions of life before birth. Berkeley, CA: North Atlantic Books. 
Cook, E. W., Pasricha, S., Samararatne, G., Maung U. W., \& Stevenson, I. (1983). A review and analysis of "unsolved" cases of the reincarnation type. II: Comparison of features of solved and unsolved cases. Journal of the American Society for Psychical Research, 77, 115-135.

Dayal, P. (1988). A case of soul transference (parakaya pravesh). Proceedings of All-India Conference on Reincarnation, March 28 and 29, 1987 (pp. 57-61, 7782). Allahabad, India: Foundation for Reincarnation and Spiritual Research.

Fielding [Hall], H. (1898). The soul of a people. London, England, UK: Bentley and Son.

Grosso, M. (2015). The "transmission" model of mind and body: A brief history. In E. F. Kelly, A. Crabtree, \& P. Marshall (Eds.), Beyond physicalism: Toward reconciliation of science and spirituality (pp. 79-113). Lanham, MD: Rowman and Littlefield.

Haraldsson, E. (2000). Birthmarks and claims of previous-life memories: I. The case of Purnima Ekanayake. Journal of the Society for Psychical Research, $64,16-25$.

Haraldsson, E., \& Matlock, J. G. (2016). I saw a light and came here: Children's experiences of reincarnation. Hove, England, UK: White Crow Books.

Harrison, P., \& Harrison, M. (1991). The children that time forgot. New York, NY: Berkley Books. (Original work published 1983 as Life before birth)

Hearn, L. (1897). Gleanings in Buddha-fields: Studies of hand and soul in the Far East. New York, NY: Houghton Mifflin.

Holden, J. M. (2009). Veridical perception in near-death experiences. In J. M. Holden, B. Greyson, \& D. James (Eds.), The handbook of near-death experiences (pp. 185-212). Westport, CT: Praeger/ABC-CLIO.

Jung, C. G. (1954). The phenomenology of the spirit in fairy tales. In Spirit and nature (Papers from the Eranos yearbooks, Vol. 1, Bollingen Series 30 [pp. 3-45]). New York, NY: Pantheon Books.

Jung, C. G. (1959/1981). The archetypes and the collective unconscious (Collected Works of C. G. Jung, Vol. 9, Part 1) (2nd ed.). Princeton, NJ: Princeton University Press.

Kellehear, A. (1996). Experiences near death: Beyond medicine and religion. New York, NY: Oxford University Press.

Kellehear, A. (2008). Census of non-Western near-death experiences to 2005: Overview of the current data. Journal of Near-Death Studies, 26, 249-265. doi:10.17514/JNDS-2008-26-4-p249-265.

Kelly, E. F., \& Presti, D. E. (2015). A psychobiological perspective on "transmission" models. In E. F. Kelly, A. Crabtree, \& P. Marshall (Eds.), Beyond physicalism: Toward a reconciliation of science and spirituality (pp. 115-155). Lanham, MD: Rowman and Littlefield.

Lundahl, C. (1992). Angels in near-death experiences. Journal of Near-Death Studies, 11, 49-56. doi:10.17514/JNDS-1992-11-1-p49-56.

Marshall, P. (2015). Why we are conscious of so little: A neo-Leibnizian approach. In E. F. Kelly, A. Crabtree, \& P. Marshall (Eds.), Beyond physicalism: Toward reconciliation of science and spirituality (pp. 387-422). Lanham, MD: Rowman \& Littlefield.

Matlock, J. G. (1990). Past life memory case studies. In S. Krippner (Ed.), Advances in parapsychological research 6 (pp. 184-267). Jefferson, NC: McFarland. 
Matlock, J. G. (n.d.). Historical near-death and reincarnation-intermission experiences of the Tlingit Indians: Case studies and theoretical reflections. Unpublished $\mathrm{ms}$.

McClenon, J. (1994). Wondrous events: Foundations of religious belief. Philadelphia, PA: University of Pennsylvania Press.

Mills, A. (1989). A replication study: Three cases of children in northern India who are said to remember a previous life. Journal of Scientific Exploration, 3, 133-184.

Mills, A., \& Dhiman, K. (2011). Shiva returned in the body of Sumitra: A posthumous longitudinal study of the significance of the Shiva/Sumitra case of the possession type. Proceedings of the Society for Psychical Research, 59(223), $145-193$.

Muller, K. E. (1970). Reincarnation—based on facts. London, England, UK: Psychic Press.

Murphy, T. (2001a). Near-death experiences in Thailand. Journal of Near-Death Studies, 19, 161-178. doi:10.17514/JNDS-2001-19-3-p161-178.

Murphy, T. (2001b). The structure and function of near-death experiences: An algorithmic reincarnation hypothesis. Journal of Near-Death Studies, 20, 101-118. doi:10.17514/JNDS-2001-20-2-p101-118.

Murphy, T. (n.d.). Eleven Thai near-death experiences. Retrieved from https:// www.god-helmet.com/bkknde.htm.

Ohkado, M. (2015). Children's birth, womb, prelife, and past-life memories: Results of an Internet-based survey. Journal of Prenatal and Perinatal Psychology and Health, 30(1), 3-16.

Ohkado, M. (2016). A same-family case of the reincarnation type in Japan. Journal of Scientific Exploration, 30, 524-536.

Ohkado, M., \& Ikegawa, A. (2014). Children with life-between-life memories. Journal of Scientific Exploration, 28, 477-490.

Osis, K., \& Haraldsson, E. (2012). At the hour of death (rev. ed.). Guildford, Surrey, UK: White Crow Books.

Pasricha, S. (1992). A systematic survey of near-death experiences in South India. Journal of Scientific Exploration, 7, 161-171.

Pasricha, S. (2008). Near-death experiences in India: Prevalence and new features. Journal of Near-Death Studies, 26, 267-282. doi:10.17514/JNDS-200826-4-p267-282.

Pasricha, S., \& Stevenson, I. (1986). Near-death experiences in India: A preliminary report. Journal of Nervous and Mental Disease, 174, 165-170.

Rawat, K. S., \& Rivas, T. (2007). Reincarnation: The scientific evidence is building. Vancouver, BC, Canada: Writers.

Rivas, T. (2001). The case of S: Possible recollections of two previous lives and of intermediate states between incarnations. Papers of Athanasia, Issue 1. Retrieved from https://www.academia.edu/768154/The_case_of_S_Possible_ recollections_of_2015-34-1-two_previous_lives_and_of_intermediate_states_ between_incarnations.

Rivas, T. (2003). Three cases of the reincarnation type in the Netherlands. Journal of Scientific Exploration, 17, 527-532.

Rivas, T. (2004). Six cases of the reincarnation type in the Netherlands. Paranormal Review, No. 29, 17-20.

Rivas, T., Carman, E. M, Carman, N. J., \& Dirven, A. (2015). Paranormal aspects of pre-existence memories in young children. Journal of Near-Death Studies, 34(2), 84-107. doi:10.17514/JNDS-2015-34-2-p84-107. 
Rivas, T., Dirven, A., \& Smit, R. H. (2016). The self does not die: Verified paranormal phenomena from near-death experiences. Durham, NC: International Association for Near-Death Studies.

Sahay, K. K. N. [1927]. Reincarnation: Verified cases of rebirth after death. Bareilly, India: Gupta.

Sharma, P., \& Tucker, J. B. (2004). Cases of the reincarnation type with memories from the intermission between lives. Journal of Near-Death Studies, 23, 101-118. doi:10.17514/JNDS-2004-23-2-p101-118.

Shroder, T. (1999). Old souls: The scientific evidence for past lives. New York, NY: Simon \& Schuster.

Slobodin, R. (1994). Kutchin concepts of reincarnation. In A. Mills \& R. Sobodin (Eds.), Amerindian rebirth: Reincarnation belief among North American Indians and Inuit (pp. 136-155). Toronto, Canada: University of Toronto Press.

Stevenson, I. (1974). Twenty cases suggestive of reincarnation (2nd rev. ed.). Charlottesville, VA: University Press of Virginia.

Stevenson, I. (1975). Cases of the reincarnation type. Volume I: Ten cases in India. Charlottesville, VA: University Press of Virginia.

Stevenson, I. (1977). Cases of the reincarnation type. Volume II: Ten cases in Sri Lanka. Charlottesville, VA: University Press of Virginia.

Stevenson, I. (1980). Cases of the reincarnation type. Volume III: Twelve cases in Lebanon and Turkey. Charlottesville, VA: University Press of Virginia.

Stevenson, I. (1983a). American children who claim to remember previous lives. Journal of Nervous and Mental Disease, 171, 742-748.

Stevenson, I. (1983b). Cases of the reincarnation type. Volume IV: Twelve cases in Thailand and Burma. Charlottesville, VA: University Press of Virginia.

Stevenson, I. (1997). Reincarnation and biology: A contribution to the etiology of birthmarks and birth defects (2 vols.). Westport, CT: Praeger.

Stevenson, I. (2001). Children who remember previous lives: A question of reincarnation (rev. ed.). Jefferson, NC: McFarland.

Stevenson, I. (2003). European cases of the reincarnation type. Jefferson, NC: McFarland.

Stevenson, I., \& Samararatne, G. (1988). Three new cases of the reincarnation type in Sri Lanka with written records made before verification. Journal of Scientific Exploration, 2, 217-238.

Story, F. (1975). Rebirth as doctrine and experience: Essays and case studies. Kandy, Sri Lanka: Buddhist Publishing Society.

Sutherland, C. (2009). Trailing clouds of glory: The near-death experiences of children and teens. In J. M. Holden, B. Greyson, \& D. James (Eds.), The handbook of near-death experiences: Thirty years of investigation (pp. 87-107). Santa Barbara, CA: Praeger/ABC-CLIO.

Tucker, J. B. (2000). A scale to measure the strength of children's claims of previous lives: Methodology and initial findings. Journal of Scientific Exploration, 14, 571-581.

Tucker, J. B. (2005). Life before life: A scientific investigation of children's memories of a previous life. New York, NY: St. Martin's Press.

Tucker, J. B. (2013). Return to life: Extraordinary cases of children who remember past lives. New York, NY: St. Martin's Press.

Zaleski, C. (1987). Otherworld journeys: Accounts of near-death experience in medieval and modern times. New York, NY: Oxford University Press. 
